\title{
Amyloid Beta (A4) Precursor Protein: A Potential Biomarker for Recurrent Nasopharyngeal Carcinoma
}

This article was published in the following Dove Press journal: Cancer Management and Research

\author{
Xiao-Yu Li (iD ${ }^{1, *}$ \\ Hui-Ling Meng ${ }^{2, *}$ \\ Kai-Guo Li' \\ Xiao-Hui Yang' \\ Xiao-Dong Zhu (D) ${ }^{1,3}$ \\ Ling $\mathrm{Li}^{1}$ \\ Zhong-Guo Liang' \\ Xin-Bin Pan' \\ Fan-Yan Zeng' \\ Song $Q u^{1,3}$
}

'Department of Radiation Oncology, Affiliated Cancer Hospital of Guangxi Medical University, Cancer Institute of Guangxi Zhuang Autonomous Region, Nanning, Guangxi 53002I, People's Republic of China; ${ }^{2}$ Department of Radiation Oncology, Liuzhou People's Hospital, Liuzhou, Guangxi 545000, People's Republic of China; ${ }^{3}$ Key Laboratory of High-Incidence-Tumor Prevention \& Treatment, Guangxi Medical University, Ministry of Education, Nanning, Guangxi 53002I, People's Republic of China

*These authors contributed equally to this work
Correspondence: Song $\mathrm{Qu}$ Department of Radiation Oncology, Affiliated Cancer Hospital of Guangxi Medical University, Cancer Institute of Guangxi Zhuang Autonomous Region, Nanning, Guangxi 53002I, People's Republic of China

Email 13607887386@I63.com
Background and Aim: Nasopharyngeal carcinoma (NPC) is one of the most common cancers in Southern China, Southeast Asia. Radiotherapy is the main treatment for NPC. Still, about $20 \%$ of patients with NPC have a recurrence. No effective serum biomarkers are available for recurrent nasopharyngeal carcinoma (rNPC) to date. This study aimed to explore whether amyloid beta (A4) precursor protein (APP) might serve as a valuable diagnostic and prognostic biomarker for patients with rNPC.

Methods: In a previous study, a tandem mass tag-based proteomic test was performed, which screened 59 differentially expressed proteins (DEPs) between nonrecurrent nasopharyngeal carcinoma (nrNPC) and rNPC. In this study, a protein-protein interaction was conducted to screen the key proteins among the 59 DEPs. APP was validated and evaluated by enzyme-linked immunosorbent assay in 70 serum samples [recurrence $(n=35)$ and norecurrence $(n=35)$ ]. Also, the receiver operating characteristic (ROC) curve was plotted to evaluate the predictive value of APP.

Results: The area under the ROC curve was 0.666 (95\% CI: $0.514-0.818, P=0.044)$. The best cutoff point of the relative expression levels for APP was 1.23 (concentration $=16.95$ $\mathrm{ng} / \mathrm{mL}$ ), at which the sensitivity was $55.2 \%$ and the specificity was $90.9 \%$.

Conclusion: The findings indicated that APP might be a valuable diagnostic and prognostic biomarker for patients with rNPC.

Keywords: amyloid beta precursor protein, biomarker, enzyme-linked immunosorbent assay, protein-protein interaction, recurrent nasopharyngeal carcinoma

\section{Introduction}

Nasopharyngeal carcinoma (NPC) is one of the most common cancers in Southern China, Southeast Asia, which has posed a serious threat to public health in these areas. ${ }^{1}$ Radiotherapy is the main treatment for NPC. With the improvement in radiotherapy techniques, about $20 \%$ of patients with NPC still have recurrence. ${ }^{2}$ Currently, the diagnosis of rNPC relies mostly on imaging or biopsy due to lack of markers. At present, CEA is a recurrence-related biomarker for colorectal tumors. ${ }^{3}$ Some studies reported early predictive biomarkers for NPC, such as HSP27, cathepsin D and keratin $8,{ }^{5} \mathrm{AMG}$ and $\mathrm{CFB},{ }^{6}$ Galectin- $1,{ }^{7} \mathrm{SAA},{ }^{8,9}$ and EBV DNA. However, these biomarkers still lack a high predictive value in the clinic. ${ }^{10}$

In a previous study, ${ }^{11} 59$ DEPs were screened out between nrNPC and rNPC by tandem mass tag (TMT) labeling. ${ }^{12,13}$ In this study, a protein-protein interaction (PPI) analysis was performed to examine whether amyloid beta (A4) precursor 
protein (APP) could be a key protein, which was confirmed by enzyme-linked immunosorbent assay (ELISA) in new serum samples.

\section{Patients and Methods}

\section{Patients}

According to the criteria established by the Chinese staging system of nasopharyngeal carcinoma in 2008 and the UICC/AJCC staging system in 2010, 70 patients with NPC and histologically proven squamous cell carcinoma were selected, including 35 with rNPC and 35 with nrNPC. All the patients were treated with radiotherapy (a total prescribed dose $\geq 70$ Gy) using a modified linear accelerator in the Affiliated Cancer Hospital of Guangxi Medical University, China, from January 2008 to June 2015. Patients with rNPC were defined as those with tumors growing again after radical radiotherapy 6 months later; tumors reach $\mathrm{cCR}$ and $\mathrm{pCR}$ during this period. ${ }^{14,15}$ Patients with nrNPC were those with no proven recurrence or metastasis following radical radiotherapy 6 months later.

This study was approved by the Joint Ethics Committee of the Guangxi Medical University Health Authority. All human serum and clinical details were obtained from the Affiliated Cancer Hospital of Guangxi Medical University.

\section{Serum Separation}

A total of $3 \mathrm{~mL}$ of venous blood was collected from each participant. The samples were allowed to stand for $30 \mathrm{~min}$ and then centrifuged at $3000 \mathrm{rpm}$ for $10 \mathrm{~min}$. The supernatant was separated and stored in different tubes at $-80^{\circ} \mathrm{C}$. One of the tubes was used for discovering different proteins, whereas the others were prepared to validate the target proteins.

\section{PPI Network}

A total of 59 DEPs were screened out between nrNPC and rNPC by TMT labeling in a previous study. ${ }^{11}$ All protein identifiers were searched against the STRING database version 9.1 for PPI. Only interactions between the proteins belonging to the searched data set were selected, thereby excluding external candidates. STRING defines a metric called "confidence score" to define interaction confidence; all interactions having a confidence score $\geq 0.7$ (high confidence) were identified. The interaction network from STRING was visualized in Cytoscape. A graph-theoretical clustering algorithm, molecular complex detection (MCODE), was used to analyze the densely connected regions. MCODE is part of the plugin tool kit of the network analysis and visualization software Cytoscape.

\section{ELISA Validation}

Human ELISA kits were used for APP (TSZ, USA). The experimental steps were performed as recommended by the manufacturer. The serum samples were analyzed for a total of 70 patients with NPC ( $35 \mathrm{rNPC}+35 \mathrm{nrNPC})$.

\section{Statistical Analysis}

All statistical analyses were performed using the SPSS 21.0 software and GraphPad Prism 7.00. The clinical characteristics among groups were compared using the $\chi^{2}$ test and Fisher's exact test for qualitative data and $t$ test for quantitative data. In addition, the APP protein was evaluated for its capacity to distinguish between rNPC and nrNPC by making an ROC curve based on the ELISA scores. All results were considered to be significant when $P$ values were $\leq 0.05$.

\section{Results}

\section{Clinical Characteristics}

The baseline characteristics of ELISA samples in the study are listed in Table 1. No significant differences were observed between the patients with nrNPC and those with rNPC in terms of sex and clinical stage $(P>0.05)$. However, the age differed significantly between these two groups (41.77 \pm 9.46 vs $49.34 \pm 9.17, P=0.006)$.

\section{Protein-Protein Interaction (PPI) Analysis}

The PPI analysis was performed, revealing significant PPI among dysregulated proteins. These proteins formed one main cluster, suggesting many interactions within this protein

Table I Clinical Characteristics of ELISA Samples

\begin{tabular}{|c|c|c|c|c|}
\hline & & nrNPC & rNPC & $P$ value \\
\hline Sex & $\begin{array}{l}\text { Male(n) } \\
\text { Female(n) }\end{array}$ & $\begin{array}{l}17 \\
5\end{array}$ & $\begin{array}{l}27 \\
2\end{array}$ & $>0.05$ \\
\hline $\begin{array}{l}\text { Clinical } \\
\text { stage }\end{array}$ & $\begin{array}{l}\text { Low }(I+I I)(n) \\
\text { High }(I I I+I V)(n)\end{array}$ & $\begin{array}{l}4 \\
18\end{array}$ & $\begin{array}{l}4 \\
25\end{array}$ & $>0.05$ \\
\hline $\begin{array}{l}\text { Mean age } \\
\pm S D(y)\end{array}$ & & $41.77 \pm 9.46$ & $49.34 \pm 9.17$ & 0.006 \\
\hline
\end{tabular}

Note: Data are expressed as number(n) or year(y).

Abbreviations: nrNPC, nonrecurrent nasopharyngeal carcinoma; rNPC, recurrent nasopharyngeal carcinoma. 
set. According to the degree of interaction, APP (degree = 34) was chosen for further study (Figures 1 and 2).

\section{ELISA Results}

A preliminary analysis was performed to assess the potential value of APP as a serum biomarker for rNPC. The serum samples of 70 patients with NPC $(35 \mathrm{rNPC}+35$ nrNPC) were initially collected because some samples contained a low concentration, beyond the reach of the ELISA kit; only 51 patients could be identified with the concentrations of APP ( 29 rNPC +22 nrNPC). For ELISA data, the relative expression levels ( $\log 10$-transformed) of APP concentrations were normally distributed. The results showed that the relative expression levels of APP were significantly different between patients with rNPC and those with nrNPC $(1.18 \pm 0.55$ vs $0.84 \pm 0.30$, $P=0.008$, Figure 3), which was in agreement with the present discovery set. ${ }^{11}$

\section{ROC Curve Results}

An ROC curve (Figure 4) was plotted to evaluate the predictive value of APP; the area under the ROC curve was 0.666 (95\% CI: $0.514-0.818, P=0.044)$. The best cutoff point of the relative expression levels for APP was 1.23 (concentration $=16.95 \mathrm{ng} / \mathrm{mL}$ ), at which the sensitivity

\section{Complement and coagulation cascades}

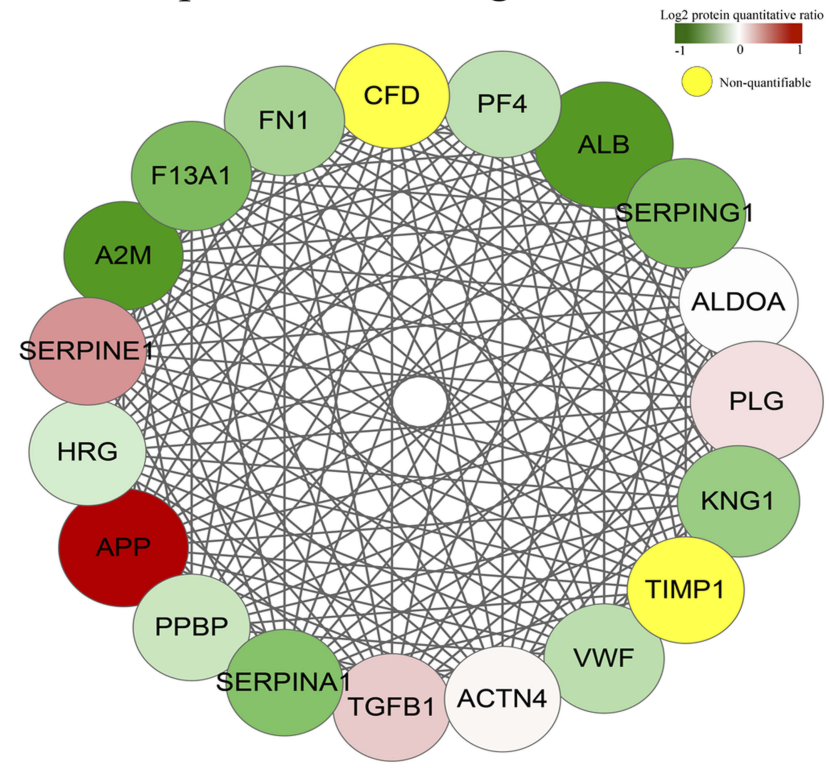

Figure 2 The cluster included 19 proteins (A2M, ACTN4, ALB, ALDOA, APP, CFD, FI3AI, FNI, HRG, KNGI, PF4, PLG, PPBP, SERPINAI, SERPINEI, SERPINGI, TIMPI, VWF) among which APP and SERPINE were up-regulated, the others were down-regulated.

was $55.2 \%$ and the specificity was $90.9 \%$. These data suggested that APP might be a promising and useful protective marker for patients with rNPC.

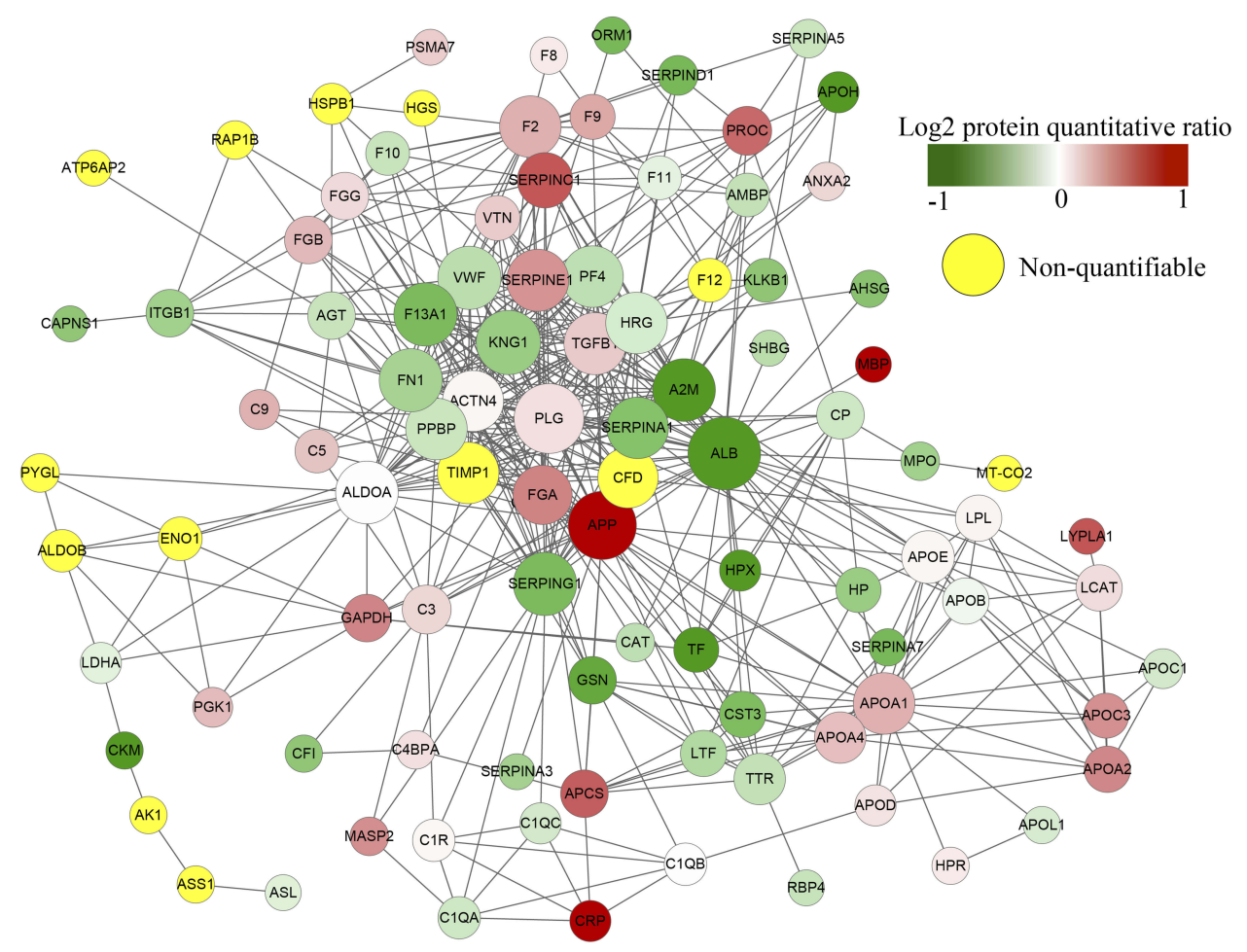

Figure I All identified protein name identifiers were searched against the STRING database version 9.1 for PPI. We found the high connective degree of APP (degree=34). 


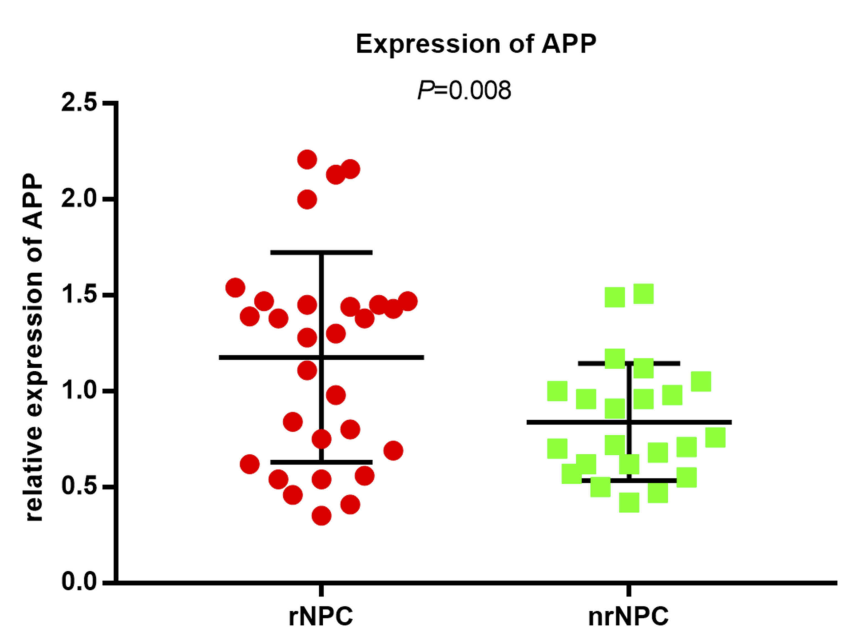

Figure 3 APP significant difference between patients with rNPC compared to $n r N P C$ in the levels of serum $(P=0.008)$.

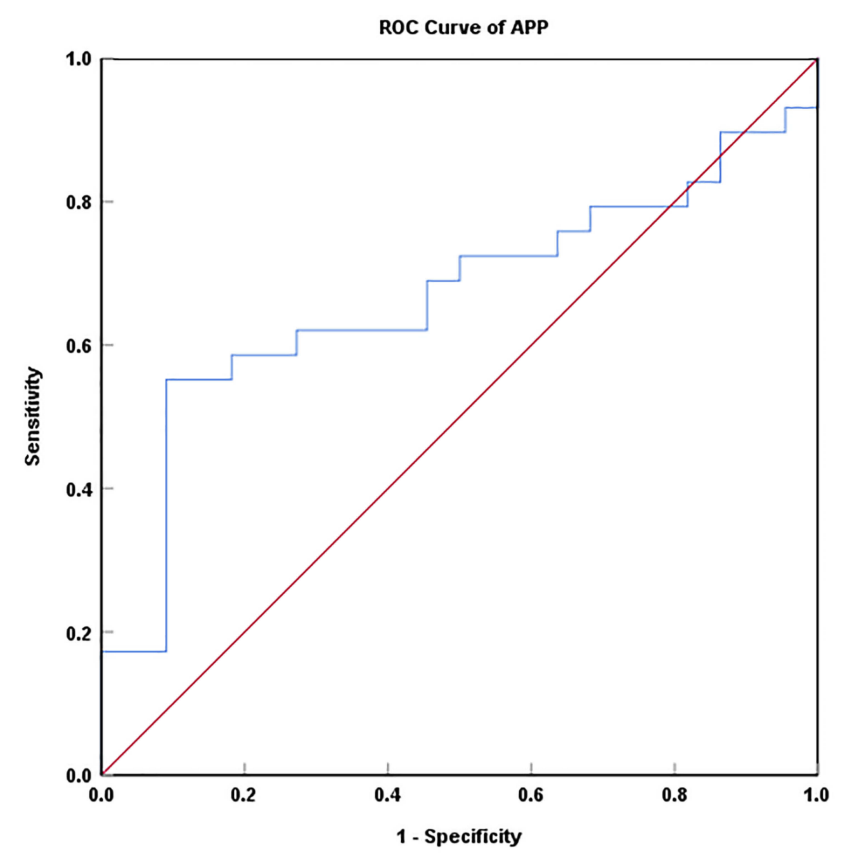

Figure 4 The area under the ROC curve was $0.666(95 \% \mathrm{Cl}: 0.514-0.818$, $P=0.044)$. The best cutoff point of the relative expression levels for APP was 1.23 (concentration $=16.95 \mathrm{ng} / \mathrm{mL}$ ), at which the sensitivity was $55.2 \%$ and the specificity was $90.9 \%$.

\section{Discussion}

The lack of biomarkers for distinguishing rNPC in an early stage is a huge challenge. However, imaging techniques, such as computed tomography or magnetic resonance imaging, has limited accuracy and cannot confirm the nature of the lesion. Moreover, a biopsy is an invasive approach with some side effects. Developing a noninvasive blood-based test may be a revolutionary step in tumor diagnosis. In this study, a comprehensive PPI analysis was conducted to identify promising biomarkers that can be further studied as noninvasive tests for diagnosing rNPC.

NPC is a multifactorial disease, including host genetics, chronic infection by EBV, environmental factors, and others. ${ }^{16}$ Further, $20 \%$ of patients with NPC still have a recurrence even after effective treatments. A well-known cause for local recurrence is radioresistance. ${ }^{17}$ Figuring out the molecular mechanism and the potential pathways involved in rNPC carcinogenesis would be very important for improving the diagnosis and treatment of rNPC.

APP was famous as the Alzheimer's disease-associated amyloid precursor protein, which was reported to be overexpressed in various cancers, such as pancreatic cancer, ${ }^{18,19}$ prostate cancer $^{20,21}$ and colon carcinoma. ${ }^{22}$ A published report ${ }^{23}$ demonstrated that APP was one of EGFR-regulated secreted proteins in NPC; it validated that APP was upregulated in not only NPC cells but also NPC tissue. The pathogenesis of NPC may involve the upregulation of secretory APP by EGFR. Interestingly, the result was in agreement with previous findings, ${ }^{23}$ implying that APP would be a promising biomarker.

Interestingly, a previous study ${ }^{11}$ concluded that $\mathrm{A} 2 \mathrm{M}$ could be a potential biomarker for rNPC. Moreover, A2M and APP were reported to be connected to each other. They both were factors related to Alzheimer's disease. A2M formed a stable complex with APP with a binding energy score. Some studies ${ }^{24,25}$ explored the effect of mutations on the APP-A2M interaction, revealing that the abrogation of this interaction was possibly associated with cancer. A weakened interaction could be related to oncogenesis. Furthermore, some other reports were also in agreement with the aforementioned findings, ${ }^{20,26,27}$ which showed that clarifying the relationship between $\mathrm{A} 2 \mathrm{M}$ and APP was essential to the monitoring and treatment of tumors.

The results strongly indicated crucial roles of some special proteins in the recurrence of rNPC. They might be potential biomarkers for estimating the risk of recurrence for NPC. Most dysregulated proteins in the present study, which were reported to be involved in tumorigenesis, are worth further investigation.

This study had some limitations. First, all the serum samples were collected at different times and stored at $80^{\circ} \mathrm{C}$ in a refrigerator, leading to the loss of some vital proteins. Second, as mentioned earlier, the age differed significantly between these two groups (41.77 \pm 9.46 vs $49.34 \pm 9.17, P=0.006$ ). However, the results of Spearman correlation analysis indicated that the concentrations of APP showed no correlation with age, sex, and 
clinical stage of patients with NPC. Therefore, it was believed that the difference in APP expression between the two groups was not due to age difference. Third, the validation cohort was constructed from a small population of only 70 patients, all treated at a single institution, leading to bias in the results. Hence, the findings should be validated using a larger population from multicenter institutions in the future.

\section{Conclusions}

In conclusion, 59 DEPs were identified from serum samples between rNPC and nrNPC. APP was overexpressed in rNPC and hence might be a potential noninvasive biomarker for confirming rNPC. This finding might be of great importance for improving the management of patients with NPC.

\section{Ethical Considerations}

The authors confirm that all patients provided written informed consent, and that this study was conducted in accordance with the Declaration of Helsinki.

\section{Acknowledgments}

This study was supported by the Development and Promotion Project of Guangxi Medical and Health Appropriate Technology (S2018038) and the Key Laboratory of High-Incidence-Tumor Prevention \& Treatment (Guangxi Medical University), Ministry of Education (GJZ201607, GKZ201607, GKE2017-ZZ04, and GK2018-08).

\section{Author Contributions}

All authors contributed to data analysis, drafting or revising the article, gave final approval of the version to be published, and agree to be accountable for all aspects of the work.

\section{Disclosure}

The authors declare no conflicts of interest regarding the publication of this manuscript.

\section{References}

1. Torre LA, Bray F, Siegel RL, et al. Global cancer statistics, 2012. CA Cancer J Clin. 2015;65(2):87-108. doi:10.3322/caac.21262

2. Chen ZT, Liang ZG, Zhu XD. A review: proteomics in nasopharyngeal carcinoma. Int J Mol Sci. 2015;16(7):15497-15530. doi:10.3390/ ijms 160715497

3. Nicholson BD, Shinkins B, Pathiraja I, et al. Blood CEA levels for detecting recurrent colorectal cancer. Cochrane Database Syst Rev. 2015;(12):CD011134. doi:10.1002/14651858.CD011134.pub2
4. Li GP, Wang H, Lai YK, et al. Proteomic profiling between CNE-2 and its strongly metastatic subclone S-18 and functional characterization of HSP27 in metastasis of nasopharyngeal carcinoma. Proteomics. 2011;11(14):2911-2920. doi:10.1002/pmic.201000483

5. Xiao Z, Li G, Chen Y, et al. Quantitative proteomic analysis of formalin-fixed and paraffin-embedded nasopharyngeal carcinoma using iTRAQ labeling, two-dimensional liquid chromatography, and tandem mass spectrometry. $J$ Histochem Cytochem. 2010;58 (6):517-527. doi:10.1369/jhc.2010.955526

6. Seriramalu R, Pang WW, Jayapalan JJ, et al. Application of champedak mannose-binding lectin in the glycoproteomic profiling of serum samples unmasks reduced expression of alpha- 2 macroglobulin and complement factor $\mathrm{B}$ in patients with nasopharyngeal carcinoma. Electrophoresis. 2010;31(14):2388-2395. doi:10.1002/elps.201000164

7. Tang CE, Tan T, Li C, et al. Identification of Galectin-1 as a novel biomarker in nasopharyngeal carcinoma by proteomic analysis. Oncol Rep. 2010;24:2. doi:10.3892/or_00000884

8. Cho WC, Yip TT, Yip C, et al. Identification of serum amyloid a protein as a potentially useful biomarker to monitor relapse of nasopharyngeal cancer by serum proteomic profiling. Clin Cancer Res. 2004;10:43-52. doi:10.1158/1078-0432.CCR-0413-3

9. Diamandis EP. Identification of serum amyloid a protein as a potentially useful biomarker for nasopharyngeal carcinoma. Clin Cancer Res. 2004;10(15):5293-5294. doi:10.1158/1078-0432.CCR-04-0377

10. Yang X, Dai W, Kwong DL, et al. Epigenetic markers for noninvasive early detection of nasopharyngeal carcinoma by methylation-sensitive high resolution melting. Int J Cancer. 2015;136(4):E127-135. doi:10.10 02/ijc. 29192

11. Meng HL, Zhu XD, Li L, et al. Identification of novel serum biomarkers for rNPC using TMT-based quantitative proteomic analysis. Chin J Oncol Prev Treat. 2017;9(3):167-171. doi:10.3969/j. issn.1674-5671.2017.03.01

12. Sandberg A, Branca RM, Lehtio J, Forshed J. Quantitative accuracy in mass spectrometry based proteomics of complex samples: the impact of labeling and precursor interference. $J$ Proteomics. 2014;96:133-144. doi:10.1016/j.jprot.2013.10.035

13. White NM, Masui O, Desouza LV, et al. Quantitative proteomic analysis reveals potential diagnostic markers and pathways involved in pathogenesis of renal cell carcinoma. Oncotarget. 2014;5 (2):506-518. doi:10.18632/oncotarget.1529

14. Stoker SD, Van Diessen JN, De Boer JP, et al. Current treatment options for local residual nasopharyngeal carcinoma. Curr Treat Options Oncol. 2013;14(4):475-491. doi:10.1007/s11864-013-0261-5

15. Li JG, Chen XZ, Lin SJ, HU CS. Expert consensus on the treatment of recurrent nasopharyngeal carcinoma. Chin $J$ Radiat Oncol. 2018;27(1):16-22. doi:10.3760/cma.j.issn.1004-4221.2018.01.002

16. Janvilisri T. Omics-based identification of biomarkers for nasopharyngeal carcinoma. Dis Markers. 2015;2015:762128. doi:10.1155/ 2015/762128

17. Luftig M. Heavy LIFting: tumor promotion and radioresistance in NPC. J Clin Invest. 2013;123(12):4999-5001. doi:10.1172/JCI73416

18. Woods NK, Padmanabhan J. Inhibition of amyloid precursor protein processing enhances gemcitabine-mediated cytotoxicity in pancreatic cancer cells. J Biol Chem. 2013;288(42):30114-30124. doi:10.1074/ jbc.M113.459255

19. Zheng KL, He TL, JI WP, et al. Alternative splicing of NUMB, APP and VEGFA as the features of pancreatic ductal carcinoma. Int J Clin Exp Pathol. 2015;8(6):6181-6191. PMID: 26261495.

20. Takayama K, Tsutsumi S, Suzuki T, et al. Amyloid precursor protein is a primary androgen target gene that promotes prostate cancer growth. Cancer Res. 2009;69(1):137-142. doi:10.1158/0008-5472. CAN-08-3633

21. Miyazaki T, Ikeda K, Horie-Inoue K, Inoue S. Amyloid precursor protein regulates migration and metalloproteinase gene expression in prostate cancer cells. Biochem Biophys Res Commun. 2014;452 (3):828-833. doi:10.1016/j.bbrc.2014.09.010 
22. Meng JY, Kataoka H, Itoh H, Koono M. Amyloid beta protein precursor is involved in the growth of human colon carcinoma cell in vitro and in vivo. Int $J$ Cancer. 2015;92(1):31-39. doi:10.1002/ 1097-0215(200102)9999:9999<::AID-IJC1155>3.0.CO;2-H

23. Tang CE, Guan YJ, Yi B, Li XH, Liang K. Identification of the amyloid $\beta$-protein precursor and cystatin $\mathrm{C}$ as novel epidermal growth factor receptor regulated secretory proteins in nasopharyngeal carcinoma by proteomics. J Proteome Res. 2010;9(12):6101-6111. doi: $10.1021 /$ pr100663p

24. Forbes SA, Bindal N, Bamford S, Cole C, Kok CY. COSMIC: mining complete cancer genomes in the catalogue of somatic mutations in cancer. Nucleic Acids Res. 2011;39(Database issue):D945-D950. doi:10.1093/nar/gkq929
25. Cerami E, Gao J, Dogrusoz U, Gross BE, Sumer SO. The cBio cancer genomics portal: an open platform for exploring multidimensional cancer genomics data. Cancer Discov. 2012;2(5):401-404. doi:10.1158/2159-8290.CD-12-0095

26. Hansel DE, Rahman A, Wehner S, Herzog V, Yeo CJ. Increased expression and processing of the alzheimer amyloid precursor protein in pancreatic cancer may influence cellular proliferation. Cancer Res. 2003;63(21):7032-7037. PMID: 14612490.

27. Pietrzik CU, Hoffmann J, Stöber K, Chen CY, Bauer C. From differentiation to proliferation: the secretory amyloid precursor protein as a local mediator of growth in thyroid epithelial cells. Proc Natl Acad Sci USA. 1998;95:1770-1775. doi:10.1073/pnas.95.4.1770

\section{Publish your work in this journal}

Cancer Management and Research is an international, peer-reviewed open access journal focusing on cancer research and the optimal use of preventative and integrated treatment interventions to achieve improved outcomes, enhanced survival and quality of life for the cancer patient.
The manuscript management system is completely online and includes a very quick and fair peer-review system, which is all easy to use. Visit http://www.dovepress.com/testimonials.php to read real quotes from published authors. 